\title{
Long-term oral antiarrhythmic therapy with mexiletine
}

\author{
NORMAN P. S. CAMPBELL, J. FRANK PANTRIDGE, AND \\ A. A. JENNIFER ADGEY \\ From the Cardiology Department, Royal Victoria Hospital, and Queen's University, Belfast
}

SUMMARY Forty-eight patients with ischaemic heart disease received oral mexiletine for the control or prevention of ventricular arrhythmias. The most frequently used doses were 200, 250, and $300 \mathrm{mg}$ 8-hourly. The treatment period varied from 2 days to more than 1 year (median 3 months). No ventricular arrhythmias were detected in more than one-half of the patients. Severe side effects occurred in $15(31 \%)$ of the 48 patients. Major ventricular arrhythmias were observed in $14(29 \%)$ of the 48 patients at a time when the majority had plasma concentrations within the therapeutic range. The value of mexiletine in the management of patients at risk of sudden death is likely to be limited.

Nearly two-thirds of premature deaths from coronary artery disease occur within one hour of the onset of symptoms (Bainton and Peterson, 1963). The majority of these deaths result from ventricular fibrillation (Adgey et al., 1969; Cobb et al., 1971).

Identification of those at high risk of sudden death from ventricular fibrillation is of the utmost concern. Despite earlier findings, sudden death is relatively infrequent among patients with unstable angina (Fulton et al., 1972; Duncan et al., 1976). However, survivors of acute infarction have a yearly incidence of sudden death approaching 5 per cent (KochWeser, 1972). Ventricular ectopics on a routine electrocardiogram recorded at least 3 months after myocardial infarction were a significant predictor of sudden death (Coronary Drug Project Research Group, 1973). The significance of ventricular ectopics may be increased if they are precipitated by stress or exercise (Lown et al., 1969; Lown, 1971) or if they are repetitive or fall early in the cycle (Lown and Wolf, 1971; Han and Goel, 1972; Lown et al., 1975).

Many antiarrhythmic agents are available for the management of ventricular arrhythmias in the coronary care unit but there is no satisfactory oral preparation for long-term prophylactic therapy. Procainamide was ineffective as an antiarrhythmic agent in a significant proportion of patients with sporadic ventricular arrhythmias when effectiveness was assessed by exercise stress testing or 24-hour

Received for publication 28 July 1977 ambulatory monitoring (Jelinek et al., 1974). Longterm oral administration of procainamide is associated with significant side effects. Most of these are related to the development of systemic lupus erythematosus. Quinidine was ineffective in ambulatory patients with sporadic ventricular ectopics, and moderate or severe adverse effects occurred in 29 per cent of the patients (Jelinek et al., 1974). Diphenylhydantoin is ineffective in prevention of sudden death and its long-term use is associated with significant adverse effects (Lovell, 1975). The role of beta-blocking agents in the prevention of sudden death from ischaemic heart disease is still uncertain though it has been suggested that alprenolol and practolol reduce the incidence of sudden death in patients discharged from hospital after myocardial infarction (Ahlmark et al., 1974; Wilhelmsson et al., 1974; Multicentre International Study, 1975).

Mexiletine-a type 1 antiarrhythmic agent with local anaesthetic effect (Singh and Vaughan Williams, 1972)-has been found to control ventricular arrhythmias in both the experimental and clinical situations (Allen et al., 1972; Campbell et al., 1973; Talbot et al., 1973; Campbell et al., 1975; Talbot, 1975; Talbot et al., 1976). It has been claimed that when the drug is given orally adverse effects are infrequent (Campbell et al., 1975; Talbot, 1975; Talbot et al., 1976). The purpose of this study was to assess the effectiveness of longterm oral therapy with mexiletine and the side effects associated with its administration. 


\section{Patients and methods}

Over a 14-month period from June 1973 to August 1975, 53 patients were started on maintenance treatment with oral mexiletine. The drug was stopped in error in 5 patients and these have been excluded from the subsequent analysis. Details of the remaining 48 patients are given in Table 1 . Thirty-nine patients had had a recent myocardial infarction and 9 had chronic ischaemic heart disease. Thirty-seven received the drug because of ventricular ectopics, ventricular tachycardia, or ventricular fibrillation. Ventricular ectopics were considered to require therapy when they were more than 5 per minute, consecutive, multifocal, or $\mathbf{R}$ on T. Ventricular tachycardia was defined as 5 or more consecutive ventricular ectopics. Mexiletine was given to 11 patients with acute myocardial infarction who had persistent ST segment elevation considered to be a harbinger of late ventricular arrhythmias (Wilson and Pantridge, 1973). Fifteen of the patients with acute myocardial infarction and 7 of those with chronic ischaemic heart disease had suffered a previous myocardial infarction. There was clinical and/or radiological evidence of mild or moderate left ventricular failure in 34 patients. Thirty patients had previously received 1 or more antiarrhythmic drugs (quinidine, procainamide, lignocaine, verapamil). These had proved ineffective or had produced adverse effects. At the time of entry into the study only 2 patients were receiving an antiarrhythmic drug.

During the initial administration of the drug, the electrocardiogram was continuously monitored. In those with acute myocardial infarction, monitoring was continuous for at least the first week of treatment. A loading dose of mexiletine was administered, either intravenously or by mouth, to 29 patients. These patients received 800 to $1100 \mathrm{mg}$ during the first 8 hours of therapy. At the start of the study, the oral maintenance dose was $300 \mathrm{mg}$ 8-hourly. Later, doses of 250 or $200 \mathrm{mg}$ were more commonly used. The dose was adjusted during therapy as the clinical situation demanded. Other drugs given to patients receiving mexiletine included digoxin, diuretics, diazepam, bronchodilators, and anticoagulants. Prolonged electrocardiographic monitoring was only possible when patients were in hospital. Out-patient evaluation was limited to 12-lead electrocardiograms.

Patients were fully assessed after 1 to 2 weeks, 4 weeks, 2 months, and 3 months on each individual regimen. Thereafter, they were reviewed at 3monthly intervals. At review, the clinical examination was usually carried out 1 to 2 hours after their last dose. The blood pressure was measured both lying and standing. Inquiry was made about possible adverse reactions. Blood was taken for haematological and biochemical assessment and for detection of antinuclear factor. After 6 months of treatment, the serum B12 and folic acid were determined. At each examination, blood was withdrawn immediately before, and 1 and 2 hours after a dose of the drug. After centrifugation the plasma was stored frozen and subsequently analysed for mexiletine (Kelly et al., 1973).

Therapy was maintained until stopped electively or stopped because of ineffectiveness, adverse reactions, or other complications such as further myocardial infarction. Adverse reactions have been classified as mild or severe. The former included minor subjective complaints, often not mentioned by the patients unless directly questioned, or slight objective abnormalities such as nystagmus or tremor. Severe side effects were usually associated with specific complaints or caused obvious clinical abnormalities, for example hypotension. With the exception of 1 man who refused readmission to hospital, patients were admitted at the time of drug withdrawal. The electrocardiogram was monitored continuously for at least 24 hours after the drug was stopped. One to 3 months after cessation of the drug therapy the patients were reassessed.

\section{Results}

Among patients with acute myocardial infarction, the median time from the onset of symptoms to

Table 1 Clinical details of patients receiving long-term oral mexiletine

\begin{tabular}{|c|c|c|c|c|c|c|c|c|c|c|c|c|c|}
\hline \multirow{2}{*}{$\begin{array}{l}\text { Age } \\
\text { (y) }\end{array}$} & \multirow{2}{*}{$\begin{array}{l}W t^{\star} \\
(k g)\end{array}$} & \multicolumn{2}{|c|}{$\operatorname{Sex}$} & \multicolumn{2}{|c|}{ Pathological condition } & \multicolumn{5}{|c|}{ Site of infarction } & \multicolumn{3}{|c|}{ Reason for antiarrhythmic therapy } \\
\hline & & $\boldsymbol{M}$ & $\boldsymbol{F}$ & $\begin{array}{l}\text { Recent } \\
\text { myocardial } \\
\text { infarction }\end{array}$ & $\begin{array}{l}\text { Chronic } \\
\text { IHD }\end{array}$ & Ant & Post & $A n t+$ post & $S E$ & $L B B B$ & $\begin{array}{l}\text { Persistent } \\
\text { ST segment } \\
\text { elevation }\end{array}$ & $V E S$ & $V T$ and/or $V F$ \\
\hline $\begin{array}{r}57.6 \\
\pm 1.5\end{array}$ & $\begin{array}{l}70 \cdot 0 \\
\pm 1 \cdot 41\end{array}$ & 45 & 3 & 39 & 9 & 23 & 9 & 3 & 3 & 1 & 11 & 19 & 18 \\
\hline
\end{tabular}

$\star$ Mean \pm SEM.

Ant, anterior; Ant + post, combined anterior and posterior; IHD, ischaemic heart disease; LBBB, left bundle-branch block; Post, posterior; $\mathrm{SE}$, subendocardial; VES, ventricular ectopics; VF, ventricular fibrillation; VT, ventricular tachycardia. 
starting treatment was 7 days (range $5 \frac{1}{2}$ hours to 6 weeks). The duration of therapy for the 48 patients varied from 2 days to more than 1 year: median time was 3 months.

It was possible to continue the treatment for as long as considered necessary in 25 patients. In 23 patients, it was stopped prematurely (Table 2). In 8 , it was stopped because of suspected adverse reactions, though in 3 of the 8 it was subsequently found that the adverse reactions were unlikely to be associated with mexiletine therapy. The drug was stopped in 7 patients because of failure to control arrhythmias: in 5 because of ventricular tachycardia or ventricular fibrillation and in 2 because of ventricular ectopics. It was found that 3 of these 7 patients had plasma concentrations of less than $0.75 \mu \mathrm{g} / \mathrm{ml}$. In 4 patients, mexiletine was stopped for other reasons. One developed a positive antinuclear factor and thrombocytopenia, 1 had congestive heart failure, 1 had a further myocardial infarction, and 1 developed signs of motor neurone disease. Four patients died while on treatment. One died in left ventricular failure and another from a further coronary occlusion. In the latter, the terminal rhythm was asystole. Two died at home: 1 of these deaths occurred suddenly in association with chest pain.

Six patients received the drug for less than 1 week. The mean trough concentration of mexiletine during treatment of the remaining $\mathbf{4 2}$ patients was $0.85 \pm 0.04(S E M) \mu \mathrm{g} / \mathrm{ml}$. There was a significant linear correlation between the total daily dose per $\mathrm{kg}$ body weight and the trough plasma concentration $(r=0.37: P<0.01)$. Using the highest of the concentrations measured at each visit, the mean peak concentration was found to be $1.45 \pm 0.06$ (SEM) $\mu \mathrm{g} / \mathrm{ml}$. A more accurate estimate of peak concentration was obtained in 27 patients as the drug was withdrawn. Samples were taken before and 1, 2, 4, 6 , and 8 hours after the last dose. From these results, the mean difference between the lowest (trough) and the peak concentrations was $0.76 \pm 0.11$ (SEM) $\mu \mathrm{g} / \mathrm{ml}$. The range did not differ significantly whether the last dose was 200,250 , or $300 \mathrm{mg}$. Peak concentrations were generally observed within 2 hours of the last dose. In a few patients $(16 \%)$ the peak was delayed for 6 hours or more.

\section{VENTRICULAR ARRHYTHMIAS DURING THERAPY}

Ventricular arrhythmias were detected in 23 patients, either during their hospital stay or at the out-patient clinic (Table 3). Major ventricular arrhythmias (ventricular tachycardia or ventricular fibrillation) were observed in 14 patients. Three of these patients developed ventricular tachycardia
Table 2 Mexiletine discontinued prematurely in 23 patients

\begin{tabular}{lllllll}
\hline $\begin{array}{l}\text { Suspected } \begin{array}{l}\text { lneffective } \\
\text { adveactions }\end{array} \\
\text { reathers }\end{array}$ & & \multicolumn{4}{l}{ Patients died } \\
\cline { 3 - 7 } & & LVF & Asystole & $\begin{array}{l}\text { Died at } \\
\text { home }\end{array}$ & Total \\
\hline 8 & 7 & 4 & 1 & 1 & 2 & 4 \\
\hline
\end{tabular}

LVF, left ventricular failure.

Table 3 Ventricular arrhythmias in patients receiving mexiletine

\begin{tabular}{lll}
\hline & $V E S$ & $V T$ orVF \\
\hline Total patients & $16^{\star}$ & $14^{\star}$ \\
Mean plasma concentration $(\mu \mathrm{g} / \mathrm{ml})$ & $1 \cdot 00$ & $1 \cdot 68$ \\
& $(\mathrm{~N}=11)$ & $(\mathrm{N}=10)$ \\
\hline
\end{tabular}

*7 patients had VES and VT detected on separate occasions.

$\mathrm{N}$, number of patients where plasma concentrations were determined; VES, ventricular ectopics; VF, ventricular fibrillation; $\mathrm{VT}$, ventricular tachycardia.

outside hospital. In 8 , it was possible to prevent further recurrence of arrhythmias, either by continuing mexiletine (2) or by giving it in combination with other drugs, that is verapamil, practolol, diphenylhydantoin, disopyramide, procainamide, or quinidine (6). One patient died in left ventricular failure before his treatment could be altered. In the remaining 5 , mexiletine was stopped and other treatment instituted. In 11 of the 14 patients, ventricular tachycardia or ventricular fibrillation occurred more than 3 weeks after the onset of acute myocardial infarction. The mean plasma concentration of mexiletine which failed to prevent major ventricular arrhythmias in 10 patients was $1.68 \mu \mathrm{g} / \mathrm{ml}$ (range 0.57 to $3.20 \mu \mathrm{g} / \mathrm{ml}$ ). In 6 of these 10 patients, the concentrations were $\geq 1.60 \mu \mathrm{g} / \mathrm{ml}$.

Ventricular ectopics were detected in 16 patients, despite a mean plasma concentration of $1.00 \mu \mathrm{g} / \mathrm{ml}$ (range 0.22 to $2.24 \mu \mathrm{g} / \mathrm{ml}$ ). In 5 of the patients, the plasma concentration was less than $0.75 \mu \mathrm{g} / \mathrm{ml}$. In 10 of the patients, the ventricular ectopics were observed on the electrocardiogram recorded at the out-patient clinic.

ELECTROCARDIOGRAPHIC, BIOCHEMICAL,

AND HAEMATOLOGICAL FINDINGS

No statistically significant changes were observed in the PR interval or in the duration of QRS or QTc in the 12-lead electrocardiogram. There were no significant differences between the biochemical and haematological results after mexiletine was stopped compared with those at the end of at least 2 months' treatment. Antinuclear factor was detected in 6 patients during treatment: in 1 patient the amount of fluorescence graded visually was ++ 
out of +++ . The antibody titre was not determined. Later, the platelet count in this patient fell to less than $100000 / \mathrm{mm}^{3}$. Three months after stopping the drug the platelet count was normal and antinuclear factor was present in smaller amounts. This patient had previously had an allergic reaction to quinidine.

\section{ADVERSE REACTIONS}

Adverse reactions were attributed to mexiletine in $31(65 \%)$ of the 48 patients (Table 4). After excluding those in whom other possible causes of the adverse effects might have operated, $26(54 \%)$ of the 48 patients had adverse effects. The most common side effects were tremor, nausea, and dyspepsia. Individual patients often had more than 1 adverse effect. Undoubtedly, severe side effects occurred in $15(31 \%)$ of the 48 patients. Adverse cardiovascular effects were observed in 4 patients. In 3, bradycardia (heart rate of 50 per minute or less) was associated with a systolic blood pressure of $70 \mathrm{mmHg}$ or lower. All 3 patients had had an anterior myocardial infarction. The bradycardia with hypotension occurred during the third week after the onset of symptoms of myocardial infarction. At the time of onset of bradycardia, none of these patients was receiving other antiarrhythmic drugs or digitalis. Postural hypotension in the absence of bradycardia was observed in 2 patients. In 14 of the 15 patients with severe side effects, the drug was stopped (5) or the dose reduced (9). Reduction in dosage resulted in the suppression or reduction in the severity of side effects. However, in 4 patients arrhythmias recurred. In 1 patient, no alteration was made because of the severity of the arrhythmias. No interactions were observed when mexiletine was given to patients already on other drugs, including antiarrhythmic agents.

The incidence of undoubted adverse effects was not related to the time the drug was given after the onset of acute myocardial infarction. Undoubted adverse effects occurred in $13(38 \%)$ of 34 patients treated within 4 weeks of the onset of symptoms and in $11(34 \%)$ of 32 treated after 4 weeks. Severe side effects occurred in $6(18 \%)$ treated early and in 4 $(12 \%)$ treated after 4 weeks.

After 4 weeks or more of treatment and despite
Table 5 Incidence of adverse effects related to trough plasma concentrations of mexiletine; side effects due to gastrointestinal irritation were excluded

\begin{tabular}{lllll}
\hline & \multicolumn{4}{l}{ Plasma concentrations $(\mu \mathrm{g} / \mathrm{ml})$} \\
\cline { 2 - 5 } & $<0.5$ & $0.5-$ & $1.0-$ & $\geqslant 1.5$ \\
\hline Number of & & & & \\
concentrations & 30 & 73 & 45 & 30 \\
Severe side effects & 0 & $3(4 \%)$ & $1(2 \%)$ & $6(20 \%)$ \\
Total side effects & $2(7 \%)$ & $13(18 \%)$ & $12(27 \%)$ & $16(53 \%)$ \\
\hline
\end{tabular}

Table 6 Clinical details, plasma concentrations, and side effects of mexiletine using different initial doses

\begin{tabular}{|c|c|c|c|c|c|}
\hline $\begin{array}{l}\text { Dose (mg) } \\
\text { given } \\
\text { 8-hourly }\end{array}$ & $\begin{array}{l}\text { No.of } \\
\text { patients }\end{array}$ & $\begin{array}{c}\text { Aget } \\
(y)\end{array}$ & $\begin{array}{l}W t \dagger \\
(\mathrm{kg})\end{array}$ & $\begin{array}{l}\text { Mean trough } \\
\text { plasma concentration } \\
\pm S E M(\mu \mathrm{g} / \mathrm{ml})\end{array}$ & $\begin{array}{l}\text { Undoubted } \\
\text { severe side } \\
\text { effects }\end{array}$ \\
\hline 300 & 14 & $\begin{array}{r}58 \cdot 6 \\
\pm 3 \cdot 2\end{array}$ & $\begin{array}{l}70 \cdot 4 \\
\pm 2 \cdot 3\end{array}$ & $\begin{array}{l}1 \cdot 15^{\star} \\
0 \cdot 13^{4}\end{array}$ & $6(43 \%)$ \\
\hline 250 & 17 & $\begin{array}{r}52.3 \\
\pm 3.8\end{array}$ & $\begin{array}{r}74.0 \\
\pm 1.8\end{array}$ & $\begin{array}{c}0.77^{\star} \\
\pm 0.06\end{array}$ & $3(18 \%)$ \\
\hline 200 & 16 & $\begin{array}{r}58.2 \\
\pm 2.5\end{array}$ & $\begin{array}{r}67.6 \\
\pm 2.9\end{array}$ & $\begin{array}{r}0.90 \\
\pm 0.09\end{array}$ & $4(25 \%)$ \\
\hline
\end{tabular}

$\star P<0.01$.

†Mean \pm SEM.

some adjustment of the dose, side effects remained as common as in the first weeks of treatment. However, the incidence of undoubted severe adverse effects was reduced from 11 of $48(23 \%)$ to 5 of 37 $(14 \%)$ but the difference was not statistically significant.

There was considerable variation in the plasma levels which could be tolerated. Some patients developed adverse effects with concentrations of less than $1.0 \mu \mathrm{g} / \mathrm{ml}$. Others had none, despite levels of more than $2.50 \mu \mathrm{g} / \mathrm{ml}$. When side effects resulting from gastrointestinal irritation were excluded, undoubted adverse effects occurred in association with a mean trough concentration of $1.03 \pm 0.18$ (SEM) $\mu \mathrm{g} / \mathrm{ml}$ and a mean peak level of $1.77 \pm 0.19$ (SEM) $\mu \mathrm{g} / \mathrm{ml}$. However, severe side effects occurred at a higher mean peak concentration than that associated with mild side effects $(2 \cdot 11 \pm 0.37$ (SEM) $\mu \mathrm{g} / \mathrm{ml}$ compared with $1.54 \pm 0 \cdot 18$ (SEM) $\mu \mathrm{g} / \mathrm{ml}$ ). The difference, however, failed to reach significance. The frequency of adverse effects was related to trough plasma concentrations (after at least 1 week

Table 4 Side effects observed in patients receiving mexiletine

\begin{tabular}{llllllll}
\hline & $\begin{array}{l}\text { Tremor and/or } \\
\text { nystagmus }\end{array}$ & Indigestion & Nausea & $\begin{array}{l}\text { Bradycardia } \\
\text { and hypotension }\end{array}$ & $\begin{array}{l}\text { Postural } \\
\text { hypotension }\end{array}$ & Others & Total patients \\
\hline Mild & $22(19)$ & $6(5)$ & $4(3)$ & 0 & 0 & $6(1)$ & $26(22)$ \\
Severe & $9(9)$ & $4(4)$ & $6(4)$ & $3(3)$ & $2(2)$ & $7(2)$ & $17(15)$ \\
\hline
\end{tabular}

^For examples, dizziness, twitching movements, dysphasia, and congestive heart failure.

Figures in parentheses indicate the number of patients in whom mexiletine was considered to be the only possible cause of the side effects. 
of therapy) (Table 5). Twenty per cent of trough concentrations $\geq 1.5 \mu \mathrm{g} / \mathrm{ml}$ were associated with severe adverse effects.

When comparing the effects of different dosages, only the regimens used first in each patient were considered (Table 6). There was wide interpatient variation in plasma concentrations for all dosages. Mean trough plasma concentrations were lower in those receiving $250 \mathrm{mg} 8$-hourly than in those on $200 \mathrm{mg} 8$-hourly. This difference may have occurred because those receiving the lower dose weighed less and were in the higher age range. Severe side effects followed the plasma concentrations and were, thus, least common in those receiving the $250 \mathrm{mg}$ 8-hourly regimen.

\section{Discussion}

Mexiletine has advantages as an oral antiarrhythmic agent. The mean biological half life for mexiletine in patients is 11.3 hours (N. P. S. Campbell, 1977, unpublished observations). Eight-hourly administration resulted in plasma concentrations within the therapeutic range (Campbell et al., 1977). Ventricular arrhythmias were not detected in more than half of the patients in this study during therapy.

It has been found that the intravenous administration of mexiletine is associated with a high incidence of adverse effects (Campbell et al., 1973; Talbot et al., 1973; Roos et al., 1976). However, when given orally to patients with acute myocardial infarction, it has been reported that adverse effects were infrequent though the drug has a narrow therapeutic index $(0.75$ to $2.00 \mu \mathrm{g} / \mathrm{ml}$ ) (Campbell et al., 1975, 1977) and was given in a fixed dosage (Campbell et al., 1975). Thirty-one (65\%) of the 48 patients in this study had adverse effects attributed to mexiletine. Adverse effects occurred in $26(54 \%)$ of the patients when other possible causes of such effects were excluded. In 15 patients $(31 \%$ ), the adverse effects were severe. All these severe side effects occurred more than 2 weeks after the onset of acute myocardial infarction. Other workers report an incidence of 29 per cent of adverse effects necessitating stopping the drug or reducing the dosage (Talbot et al., 1976).

The majority of the adverse effects encountered in this study have previously been described (Campbell et al., 1973). Though other workers have not reported adverse cardiovascular effects when mexiletine was given by mouth (Talbot et al., 1973; Campbell et al., 1975; Talbot et al., 1976), 3 patients in this study developed bradycardia and hypotension during therapy. All had had an anterior myocardial infarction at least 2 weeks before the development of hypotension. Two patients had received therapy for 2 weeks. Postural hypotension, which was observed in 2 patients, has not been previously documented. Saunamäki (1975) has described a fall in the peripheral resistance in patients given the drug intravenously. The drug has been reported to have negative inotropic effects (Shaw et al., 1973; Saunamäki, 1975). Though 4 patients in this study developed heart failure while on treatment, it was impossible to attribute this to mexiletine with certainty. One patient developed a positive test for antinuclear factor and thrombocytopenia which may have been caused by mexiletine.

Adverse effects are frequently dose related and in individual patients it is frequently possible to arrive at a suitable dose (Talbot et al., 1976; Campbell et al., 1977). In this study, after dosage adjustment undoubted severe adverse effects due to mexiletine occurred in $5(14 \%)$ of 37 patients continuing on the drug for 4 weeks or longer.

The therapeutic plasma concentration of mexiletine lies between 0.75 and $2.00 \mu \mathrm{g} / \mathrm{ml}$ (Campbell et al., 1975, 1977). We have shown that, using 10 to $14 \mathrm{mg} / \mathrm{kg}$ per day orally, 72 per cent of steady state plasma concentrations lie within this range (Campbell et al., 1977). In this study, important side effects occurred at a mean peak concentration of 2.11 $\mu \mathrm{g} / \mathrm{ml}$. The mean difference between trough and peak concentrations was $0.76 \mu \mathrm{g} / \mathrm{ml}$. This suggests that plasma concentrations associated with adverse effects will often occur if trough concentrations of $1.50 \mu \mathrm{g} / \mathrm{ml}$ are exceeded. Twenty per cent of trough concentrations of $\geq 1.5 \mu \mathrm{g} / \mathrm{ml}$ were associated with severe adverse effects (Table 5). It was disappointing that major ventricular arrhythmias were not prevented by plasma concentrations of $1.60 \mu \mathrm{g} / \mathrm{ml}$ or greater. Talbot et al. (1976) found that in 18 patients with ventricular arrhythmias associated with ischaemic heart disease or acute myocardial infarction, the mean minimum effective therapeutic concentration of mexiletine was $1.60 \mu \mathrm{g} / \mathrm{ml}$.

The observations among patients in this study, many of whom had cardiac failure and arrhythmias resistant to other antiarrhythmic drugs, suggest that mexiletine may be used for long-term oral therapy. Though side effects are frequent, they are usually dose related. Careful titration of the dose may allow therapy to continue but the margin between therapeutic effect and toxicity is small. Major ventricular arrhythmias (ventricular tachycardia or fibrillation) were detected in 14 patients $(29 \%)$ at a time when the majority of plasma concentrations lay within the therapeutic range. Failure to prevent major ventricular arrhythmias casts doubt on the value of mexiletine in the prevention of sudden death. 
We thank J. G. Kelly, Ph. D., for the determination of the plasma concentrations.

Preliminary results of this study have been published in the Postgraduate Medicalfournal (1977), 53, Suppl. I, 143.

\section{References}

Adgey, A. A. J., Nelson, P. G., Scott, M. E., Geddes, J. S., Allen, J. D., Zaidi, S. A., and Pantridge, J. F. (1969). Management of ventricular fibrillation outside hospital. Lancet, 1, 1169-1171.

Ahlmark, G., Saetre, H., and Korsgren, M. (1974). Reduction of sudden deaths after myocardial infarction. Lancet, 2 , 1563.

Allen, J. D., Kofi Ekue, J. M., Shanks, R. G., and Zaidi, S. A. (1972). The effect of KO 1173, a new anticonvulsant agent, on experimental cardiac arrhythmias. British fournal of Pharmacology, 45, 561-573.

Bainton, C. R., and Peterson, D. R. (1963). Deaths from coronary heart disease in persons 50 years of age and younger: a community wide study. New England fournal of Medicine, 268, 569-575.

Campbell, N. P. S., Chaturvedi, N. C., Kelly, J. G., Strong, J. E., Shanks, R. G., and Pantridge, J. F. (1973). Mexiletine (KO 1173), in the management of ventricular dysrhythmias. Lancet, 2, 404-407.

Campbell, N. P. S., Pantridge, J. F., and Adgey, A. A. J. (1977). Mexiletine in the management of ventricular dysrhythmias. European fournal of Cardiology, 6/4, 245-258.

Campbell, R. W. F., Talbot, R. G., Dolder, M. A., Murray, A., Prescott, L. F., and Julian, D. G. (1975). Comparison of procainamide and mexiletine in prevention of ventricular arrhythmias after acute myocardial infarction. Lancet, 1, 1257-1260.

Cobb, L. A., Conn, R. D., and Samson, W. E. (1971). Prehospital coronary care. The role of a rapid response mobile intensive/coronary care system (abstract). Circulation, 43 and 44, Suppl. II, 45.

Coronary Drug Project Research Group (1973). Prognostic importance of premature beats following myocardial infarction; experience in the Coronary Drug Project. Fournal of the American Medical Association, 223, 1116-1124.

Duncan, B., Fulton, M., Morrison, S. L., Lutz, W., Donald, K. W., Kerr, F., Kirby, B. J., Julian, D. G., and Oliver, M. F. (1976). Prognosis of new and worsening angina pectoris. British Medical fournal, 1, 981-985.

Fulton, M., Duncan, B., Lutz, W., Morrison, S. L., Donald, K. W., Kerr, F., Kirby, B. J., Julian, D. G., and Oliver, M. F. (1972). Natural history of unstable angina. Lancet, 1, 860-865.

Han, J., and Goel, B. G. (1972). Electrophysiologic precursors of ventricular tachyarrhythmias. Archives of Internal Medicine, 129, 749-755.

Jelinek, M. V., Lohrbauer, L., and Lown, B. (1974). Antiarrhythmic drug therapy for sporadic ventricular ectopic arrhythmias. Circulation, 49, 659-666.

Kelly, J. G., Nimmo, J., Rae, R., Shanks, R. G., and Prescott, L. F. (1973). Spectrophotofluorometric and gas-liquid chromatographic methods for the estimation of mexiletine (KÖ 1173) in plasma and urine. Fournal of Pharmacy and Pharmacology, 25, 550-553.

Koch-Weser, J. (1972). Antiarrhythmic prophylaxis in ambulatory patients with coronary heart disease. Archives of Internal Medicine, 129, 763-772.

Lovell, R. R. H. (1975). Arrhythmia prophylaxis. Long-term suppressive medication. Circulation, 51 and 52, Suppl. III, 236-240.

Lown, B. (1971). Arrhythmias and sudden death. In The Prodromal Symptoms of Myocardial Infarction and Sudden Death. Report on a Working Group convened by the Regional Office for Europe of the World Health Organisation Copenhagen EURO 8204 (3), pp. 17-19. WHO, Copenhagen.

Lown, B., Kosowsky, B., and Whiting, R. (1969). Exposure of electrical instability in coronary artery disease by exercise stress (abstract). Circulation, 39 and 40, Suppl. III, 136.

Lown, B., Calvert, A. F., Armington, R., and Ryan, M. (1975). Monitoring for serious arrhythmias and high risk of sudden death. Circulation, 51 and 52, Suppl. III, 189-198.

Lown, B., and Wolf, M. (1971). Approaches to sudden death from coronary heart disease. Circulation, 44, 130-142.

Multicentre International Study (1975). Improvement in prognosis of myocardial infarction by long-term betaadrenoreceptor blockade using practolol. British Medical Fournal, 3, 735-740.

Roos, J. C., Paalman, A. C. A., and Dunning, A. J. (1976). Electrophysiological effects of mexiletine in man. British Heart fournal, 38, 1262-1271.

Saunamäki, K. I. (1975). Haemodynamic effects of a new antiarrhythmic agent, mexiletine (KO 1173) in ischaemic heart disease. Cardiovascular Research, 9, 788-792.

Shaw, T. R. D., Royds, R., and Hamer, J. (1973). Effects of KÖ 1173, a new antiarrhythmic drug, on contractile state of diseased left ventricle and on frequency of 'stable' premature beats (abstract). British Heart fournal, 35, 558.

Singh, B., and Vaughan Williams, E. M. (1972). Investigations of the mode of action of a new antidysrhythmic drug, KÖ 1173. British fournal of Pharmacology, 44, 1-9.

Talbot, R. G. (1975). Mexiletine. American Heart fournal, 88, 537-538.

Talbot, R. G., Clark, R. A., Nimmo, J., Neilson, J. M. M., Julian, D. G., and Prescott, L. F. (1973). Treatment of ventricular arrhythmias with mexiletine (Kठ 1173). Lancet, 2, 399-404.

Talbot, R. G., Julian, D. G., and Prescott, L. F. (1976), Long-term treatment of ventricular arrhythmias with oral mexiletine. American Heart fournal, 91, 58-65.

Wilhelmsson, C., Vedin, J. A., Wilhelmsen, L., Tibblin, G., and Werkö, L. (1974). Reduction of sudden deaths after myocardial infarction by treatment with alprenolol. Lancet, 2, 1157-1160.

Wilson, C., and Pantridge, J. F. (1973). ST-segment displacement and early hospital discharge in acute myocardial infarction. Lancet, 2, 1284-1288.

Requests for reprints to $\mathrm{Dr}$ A. A. Jennifer Adgey, Cardiology Department, Royal Victoria Hospital, Grosvenor Road, Belfast BT12 6BA, Northern Ireland. 